\title{
Evaluation of the Anxiolytic and Antidepressant Activities of the Aqueous Extract from Camellia euphlebia Merr. ex Sealy in Mice
}

\author{
Dongye He, ${ }^{1,2}$ Xitao Wang, ${ }^{1}$ Ping Zhang, ${ }^{1,2}$ Xinxing Luo, ${ }^{1,2}$ Xiaoyu Li, ${ }^{1,2}$ Lili Wang, \\ Shuying $\mathrm{Li}^{3}$, and Yongping $\mathrm{Xu}^{1,2,3}$ \\ ${ }^{1}$ School of Life Science and Biotechnology, Dalian University of Technology, Dalian 116024, China \\ ${ }^{2}$ Ministry of Education Center for Food Safety of Animal Origin, Dalian University of Technology, Dalian 116620, China \\ ${ }^{3}$ Dalian SEM Bio-Engineering Technology Co. Ltd., Dalian 116620, China
}

Correspondence should be addressed to Yongping Xu; hechen2287@gmail.com

Received 8 July 2015; Revised 14 August 2015; Accepted 16 August 2015

Academic Editor: David Mischoulon

Copyright $\odot 2015$ Dongye He et al. This is an open access article distributed under the Creative Commons Attribution License, which permits unrestricted use, distribution, and reproduction in any medium, provided the original work is properly cited.

Camellia euphlebia Merr. ex Sealy is a traditional Chinese medicine that has been widely used for improvement of human emotions in the Guangxi Province of southern China. However, there are no studies about the anxiolytic and antidepressant activities of Camellia euphlebia. This study evaluated the anxiolytic and antidepressant activities of the aqueous extract from Camellia euphlebia (CEE) in mice. We found that administration of $400 \mathrm{mg} / \mathrm{kg}$ CEE or $20 \mathrm{mg} / \mathrm{kg}$ fluoxetine for 7 days significantly reduced the immobility time in both TST and FST. Oral administration of $100 \mathrm{mg} / \mathrm{kg}$ extract or $4 \mathrm{mg} / \mathrm{kg}$ diazepam for 7 days significantly increased the percentage of time spent and the number of entries into the open arms of the EPMT. In addition, the time spent by mice in the illuminated side of the LDBT was increased. Furthermore, pretreatment with $400 \mathrm{mg} / \mathrm{kg}$ CEE for 7 days significantly elevated the level of 5-HT and DA in the whole brain of mice. These results provide support for the potential anxiolytic and antidepressant activity of Camellia euphlebia and contribute towards validation of the traditional use of Camellia euphlebia in the treatment of emotional disorders.

\section{Introduction}

Approximately 450 million people worldwide suffer from mental illness or behavioral disorders, which account for $12.3 \%$ of the global burden of disease [1]. It is estimated that this percentage will reach $15 \%$ by 2020 [2]. Among the many mental illnesses and behavioral disorders, depression and anxiety are the two most prevalent psychiatric disorders [3]. Several classical anxiolytic and antidepressant drugs such as benzodiazepines, monoamine oxidase inhibitors, tricyclic antidepressants, selective serotonin reuptake inhibitors, serotonin-norepinephrine reuptake inhibitors, and noradrenergic and specific serotonergic antidepressants are widely used in clinical practice to treat these disorders. However, treatment by the above-mentioned drugs can also bring undesirable side effects including cardiovascular toxicity, sexual dysfunction, weight gain, and drug interactions [4-6]. Therefore, there is an urgent need for the development of effective anxiolytic and antidepressant therapies without any or at least fewer adverse effects.

In recent years, many traditional Chinese medicinal plants such as Acanthopanax senticosus [7], Acorus calamus [8], Albizia julibrissin [9], Ginkgo biloba [10], Paeonia lactiflora [11], and Hypericum perforatum [12] have been successfully used to prevent or treat anxiety and depression. Thus, traditional Chinese medicines may be effective alternatives for the treatment of psychiatric disorders.

Camellia euphlebia Merr. ex Sealy (Theaceae), called Fortune's Yellow Camellia, is an evergreen shrub standing about 2 to $5 \mathrm{~m}$ in height, found in the Guangxi Zhuang Autonomous Region of southern China. The leaves of Camellia euphlebia are commonly used for the treatment of dysentery, hypertension, diarrhea, faucitis, and irregular menstruation. The extracts of Camellia euphlebia were reported 
to possess anticarcinogenic, antioxidant, hypoglycemic, and hypolipidemic properties [13-16]. Phytochemical studies on the leaf extract have shown the presence of theanine $(\gamma$ glutamylethylamide), $\gamma$-aminobutyric acid (GABA), and caffeine, which can exert different degrees of neuroprotection $[13,17-19]$. However, the use of the leaf extract of Camellia euphlebia (CEE) has yet to be supported by pharmacological data to prove its anxiolytic and depressant effects.

The present study investigated the anxiolytic activities of CEE in mice, at doses of 100,200 , and $400 \mathrm{mg} / \mathrm{kg} / \mathrm{day}$, using the light-dark box test (LDBT) and the elevated plus-maze test (EPMT), and investigated the antidepressant activities of CEE by the forced swimming test (FST) and tail suspension test (TST).

\section{Materials and Methods}

2.1. Plant Material and Preparation of the Aqueous Extract. Fresh leaves of Camellia euphlebia Merr. ex Sealy were obtained in Guangxi Zhuang Autonomous Region during its flowering period and authenticated by Ph.D. Zhonghhui $\mathrm{Ma}$ (Department of Botany Sciences, College of Agriculture, Guangxi University, China). A voucher specimen with number 8109255 has been deposited in the herbarium of the Guangxi Institute of Botany, Chinese Academy of Sciences, China.

The fresh leaves were washed three times with tap water and then dried at $55^{\circ} \mathrm{C}$ for $6 \mathrm{~h}$ in a forced air oven. The dried leaves were ground into a coarse powder with a pulverizer (HC-150T2, Yongkang Lv Ke Food Machinery Company, Zhejiang, China) at room temperature and then further ground through a 200 mesh sieve to obtain a fine powder. Twenty grams of the fine power was extracted twice with $400 \mathrm{~mL}$ distilled water $(1: 20)$ for $2 \mathrm{~h}$ at $100^{\circ} \mathrm{C}$ using an electrical heating jacket (ZNHW, Gongyi Zi Hua Instrument Company, Henan, China) with occasional stirring. Thereafter, the mixture was centrifuged at $10,000 \mathrm{rpm}$ for $10 \mathrm{~min}$ and the supernatant was filtered using a $0.22 \mu \mathrm{m}$ Millipore Filter (Merck Millipore, Billerica, MA, USA) to remove particulate matter. A lyophilized powder with a yield of $19.3 \%(\mathrm{w} / \mathrm{w})$ was prepared using a freeze dryer (FD1A-50, Beijing Bo Kang Experimental Medical Instrument Company, Beijing, China) and stored in a sealed bag at $-20^{\circ} \mathrm{C}$ until use.

2.2. Animals. Male Kunming mice, weighing 20 to $25 \mathrm{~g}$, were purchased from the Experimental Animal Centre of Dalian Medical University (Dalian, China). The animals were housed with a $12 \mathrm{~h}$ light/dark cycle under controlled humidity $(50 \pm$ $10 \%)$ and temperature $\left(22 \pm 2^{\circ} \mathrm{C}\right)$ and were allowed free access to food and water. The animals were acclimatized for at least 3 days before they were tested and were randomly assigned to the various experimental groups ( $n=6$ per group). All animal experiments were performed in compliance with the recommendations of the Local Institutional Animal Care and National Act on the use of experimental animals (Beijing, China).

2.3. Drugs and Administration. For each test, mice were divided into five groups including vehicle control, positive control, and three experimental groups. Animals in the vehicle control group were administered normal saline $(0.9 \%$ $\mathrm{NaCl}$ solution). In the antianxiety tests, the positive control group was treated with $4 \mathrm{mg} / \mathrm{kg}$ diazepam (DZP, Sigma, St Louis, MO) as an anxiolytic drug, while in the antidepression tests, the positive control group was treated with $20 \mathrm{mg} / \mathrm{kg}$ fluoxetine (FLU, Patheon, Jallieu Cedex, France) as an antidepressant drug. Mice in the three experimental groups were administered CEE at doses of 100, 200, or $400 \mathrm{mg} / \mathrm{kg}$. All administrations were performed in a volume of $0.4 \mathrm{~mL}$ per $25 \mathrm{~g}$ body weight. All drugs were administrated only once per day via gastric intubation between 9:30 and 10:30 a.m. for 7 consecutive days. The tests were conducted $1 \mathrm{~h}$ after the last drug treatment.

2.4. Acute Toxicity Study. Mice (10 per treatment) were treated orally with normal saline $(0.4 \mathrm{~mL}$ per $25 \mathrm{~g})$ or CEE $(500,1000,2000$, or $4000 \mathrm{mg} / \mathrm{kg})$ between 9:00 and 10:00 a.m. Each intragastric administration was performed after a $6 \mathrm{~h}$ fasting period. Mice were observed for toxic symptoms and mortality was calculated after $24 \mathrm{~h}$ of the last-treatment [20].

\subsection{Antianxiety Tests in Mice}

2.5.1. Light-Dark Box Test (LDBT). The light-dark box test was carried out according to the method of Costall et al. [21]. The test apparatus consisted of a plexiglass box (length $45 \mathrm{~cm}$ $\times$ width $27 \mathrm{~cm} \times$ height $27 \mathrm{~cm}$ ) with two compartments with $40 \%$ dark area and $60 \%$ brightly illuminated white area. Mice were placed individually into the center of the illuminated compartment, facing one of the light areas. The time spent in the light box was recorded for $5 \mathrm{~min}$. Entrance into the light box was regarded as an index of less anxiety [22].

2.5.2. Elevated Plus-Maze Test (EPMT). The elevated plusmaze test was carried out according to the method described by Carrasco et al. [23]. The test apparatus consisted of two enclosed arms (length $30 \mathrm{~cm} \times$ width $5 \mathrm{~cm} \times$ height $15 \mathrm{~cm}$ ), two open arms (length $30 \mathrm{~cm} \times$ width $5 \mathrm{~cm}$ ), and a central platform $(5 \mathrm{~cm} \times 5 \mathrm{~cm})$. The maze was elevated $45 \mathrm{~cm}$ above the floor level. Mice were placed individually into the center of the maze, facing one of the open arms. The number of open arms entries and the time spent in the enclosed and open arms were recorded for $5 \mathrm{~min}$ with a video camera. Increased activity in the open arms was indicative of less anxiety [24]. Entry into an arm was defined when mice placed all four feet into the arm. The maze was cleaned with $10 \%$ ethanol solution after each test.

\subsection{Antidepression Tests in Mice}

2.6.1. Forced Swimming Test (FST). The forced swimming test was based on the method of Porsolt et al. [25]. Briefly, mice were forced to swim individually in a glass cylinder $(20 \mathrm{~cm} \times$ $14 \mathrm{~cm}$ ) containing fresh water up to a height of $10 \mathrm{~cm}$ at $25 \pm$ $1^{\circ} \mathrm{C}$. All animals were forced to swim for a $6 \mathrm{~min}$ period and the total duration of immobility was recorded during the last 4 min with a video camera. Mice were considered immobile when they floated in the water without struggling and making 
only those movements necessary to keep their heads above the water.

2.6.2. Tail Suspension Test (TST). The tail suspension test was conducted as previously described by Steru et al. [26]. Briefly, mice were suspended individually $5 \mathrm{~cm}$ above the floor by an adhesive tape placed approximately $1 \mathrm{~cm}$ from the tip of the tail. Testing was carried out in a darkened room with minimal background noise. Mice were considered to be immobile only when they hung passively or remained completely motionless. The total duration of immobility was recorded during the final $4 \mathrm{~min}$ of the $6 \mathrm{~min}$ test and scored by an observer blind to treatment.

2.7. Open-Field Test (OFT). To exclude nonspecific effects of CEE, the spontaneous locomotor activity of mice was measured in the open-field test. The test was carried out on mice according to a slightly modified method [27]. The apparatus consisted of an opaque-plexiglass box $(40 \mathrm{~cm} \times$ $40 \mathrm{~cm} \times 40 \mathrm{~cm}$ ) with the floor divided equally into 25 squares. Mice were placed individually into the center of the arena and allowed to explore freely. The number of crossings (number of squares crossed by the mouse with the four paws) and the number of rearing (standing on the hind legs) were recorded for $3 \mathrm{~min}$.

2.8. Determination of Monoamine Neurotransmitter Levels. After the tail suspension test, mice were sacrificed immediately by decapitation, and the whole brain was quickly removed, frozen in liquid nitrogen, and stored at $-70^{\circ} \mathrm{C}$ for biochemical analysis. The whole brain tissue was homogenized using a Teflon-glass homogenizer. A $30 \mathrm{mg}$ portion of the homogenate was diluted in $300 \mu \mathrm{L}$ normal saline $(0.9 \%)$ and then centrifuged at $10000 \mathrm{~g}$ for $10 \mathrm{~min}$ at $4^{\circ} \mathrm{C}$. The levels of 5-HT and DA in the supernatant were measured by ELISA (Nanjing Jiancheng Bioengineering Institute, Nanjing, China). Dispensed antigen standards and samples were added to each well of 96-well plates precoated with primary antibodies. After adding biotin conjugate reagent and enzyme conjugate reagent into each well, the plates were incubated at $37^{\circ} \mathrm{C}$ for $60 \mathrm{~min}$. Then the plates were rinsed five times with wash solution. Within 10 min of the chromogenic reaction, the absorbance was measured at $450 \mathrm{~nm}$ using a microplate reader (TECAN, Sunrise, Männedorf, Austria).

2.9. Statistical Analysis. The data were statistically analyzed with one-way analysis of variance (ANOVA) followed by Tukey's $t$-test using GraphPad Prism 5.03 Software (GraphPad Software Inc., San Diego, CA, USA). The results were expressed as the mean \pm standard error (S.E.M.). Differences among groups were considered to be statistically significant at $P<0.05$.

\section{Results}

3.1. Acute Toxicity Study. The aqueous extract (500 to $4000 \mathrm{mg} / \mathrm{kg}$ ) had a high safety profile, as no deaths were observed at the dose levels tested. The behavioral changes
TABLE 1: Effects of oral administration of CEE (500, 1000, 2000, or $4000 \mathrm{mg} / \mathrm{kg})$ or normal saline $(0.4 \mathrm{~mL} / 25 \mathrm{~g})$ on toxic symptoms and mortality in mice.

\begin{tabular}{lccc}
\hline Drug & Dose $(\mathrm{mg} / \mathrm{kg})$ & Mortality $(\%)$ & $\begin{array}{c}\text { Symptoms of } \\
\text { toxicity* }\end{array}$ \\
\hline Saline & - & 0 & None \\
CEE & 500 & 0 & None \\
CEE & 1000 & 0 & None \\
CEE & 2000 & 0 & Sedation \\
CEE & 4000 & 0 & $\begin{array}{c}\text { Sedation, } \\
\text { hyperventilation }\end{array}$ \\
\hline
\end{tabular}

${ }^{*}$ The toxic symptoms include sedation, hypoactivity, loss of appetite, piloerection, convulsion, dizziness, syncope, and hyperventilation.

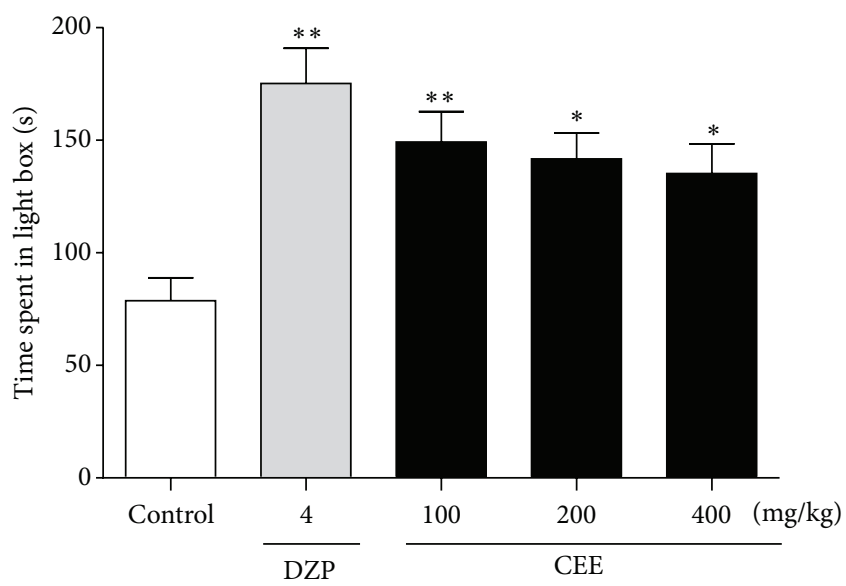

FIGURE 1: Effects of oral administration of CEE (100, 200, or $400 \mathrm{mg} / \mathrm{kg})$ or diazepam $(4 \mathrm{mg} / \mathrm{kg})$ on the time spent in the illuminated side of the light-dark box test in mice. The total time spent in the light box was recorded $1 \mathrm{~h}$ after the last administration. Values are presented as mean \pm S.E.M. $\left(n=6\right.$ per group). ${ }^{*} P<0.05$, ${ }^{* *} P<0.01$ as compared with vehicle control.

observed at high doses of CEE (2000 or $4000 \mathrm{mg} / \mathrm{kg}$ ) were sedation and hyperventilation (Table 1 ).

3.2. Effects of CEE on the Time Spent in the Illuminated Side of the LDBT. As is shown in Figure 1, compared with control group, the oral administration of CEE at doses of 100, 200 , or $400 \mathrm{mg} / \mathrm{kg}$ as well as $4 \mathrm{mg} / \mathrm{kg}$ diazepam significantly increased the time spent in the light box by mice $[P<0.01$, $P<0.05, P<0.05$, and $P<0.01$, resp.]. Moreover, in this test, the anxiolytic effects of CEE were dose-dependent with a trend to decline after 7 consecutive days of treatment.

3.3. Effects of CEE on Mice Behavior in the EPMT. The results presented in Figure 2(a) indicate that treating mice with CEE at doses of $100(P<0.01)$ or $200 \mathrm{mg} / \mathrm{kg}(P<0.05)$ for 7 days significantly increased the percentage of open arm entries by 76.77 and $71.24 \%$, respectively, compared with the control group. However, the difference between the control and the dose of $400 \mathrm{mg} / \mathrm{kg}$ was not statistically significant.

Figure 2(b) showed that treatment with CEE at a dose of $100 \mathrm{mg} / \mathrm{kg}$ resulted in statistically significant changes in 


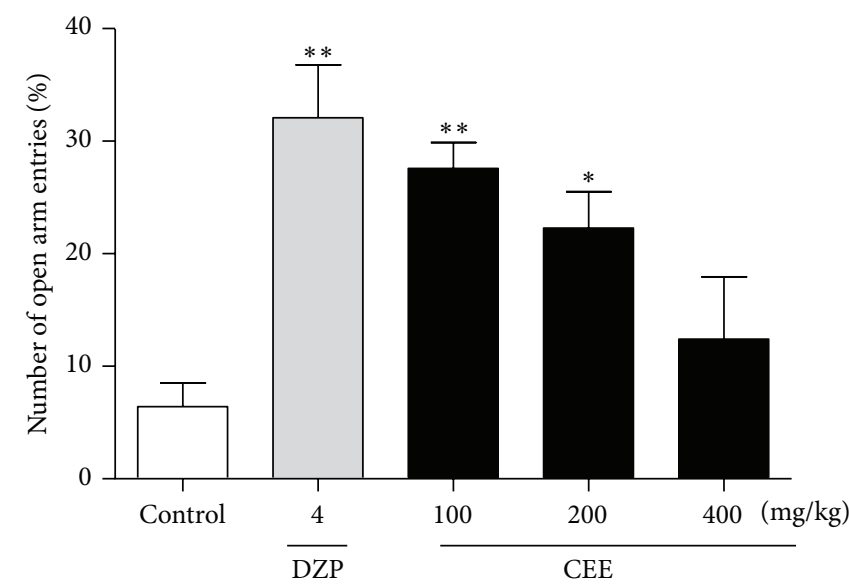

(a)

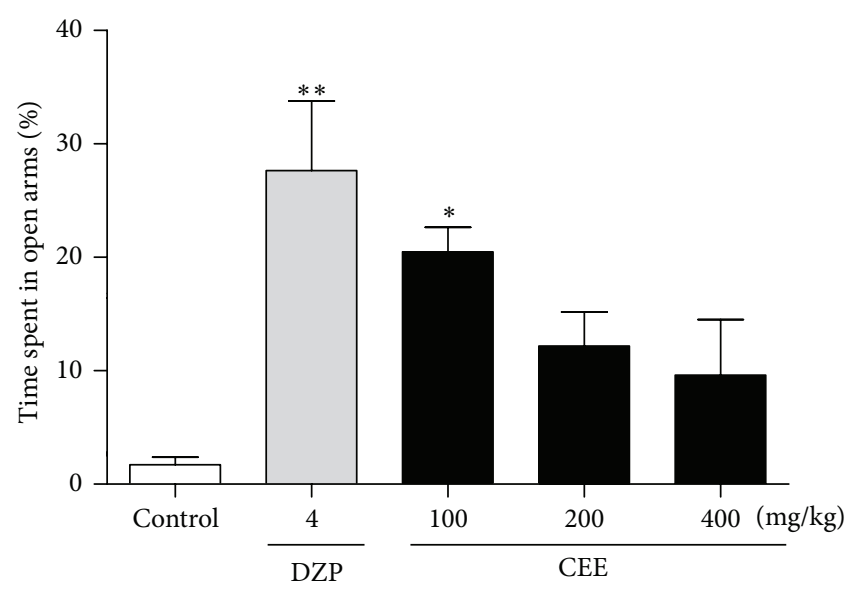

(b)

Figure 2: Effects of oral administration of CEE $(100,200$, or $400 \mathrm{mg} / \mathrm{kg})$ or diazepam $(4 \mathrm{mg} / \mathrm{kg})$ on the behaviors in the elevated plus-maze test in mice. The total time spent in the light box was recorded $1 \mathrm{~h}$ after the last administration. (a) The number of open arm entries during the total $5 \mathrm{~min}$ test in mice. (b) The time spent in open arms during the total $5 \mathrm{~min}$ test in mice. Values are presented as mean \pm S.E.M. $(n=6$ per group). ${ }^{*} P<0.05,{ }^{* *} P<0.01$ as compared with vehicle control.

the percentage of time spent in the open arm compared with the control group $(P<0.05)$, while the doses of 200 and $400 \mathrm{mg} / \mathrm{kg}$ were not statistically significant. In addition, diazepam $(4 \mathrm{mg} / \mathrm{kg})$ as a widely used anxiolytic drug in clinical practice significantly increased the percentage of open arm entries and the percentage of time spent in the open arms in the EPMT, by 80.03 and $93.75 \%$, respectively $(P<0.01)$.

3.4. Effects of CEE on the Duration of Immobility in the FST. The antidepressant effect of CEE was investigated in the forced swimming test. The results in Figure 3 showed that, compared with the control group, CEE at a dose of $400 \mathrm{mg} / \mathrm{kg}$ significantly decreased the duration of immobility $(P<0.05)$, resulting in a $37.34 \%$ immobility reduction, while animals administrated with CEE at doses of 100 and $200 \mathrm{mg} / \mathrm{kg}$ demonstrated no statistically significant increase in the duration of immobility. Additionally, fluoxetine, a classical antidepressant agent, caused a significant reduction in the immobility time $(P<0.01)$ in the FST (78.47\%).

3.5. Effects of CEE on the Duration of Immobility in the TST. The effects of CEE on the duration of immobility in the tail suspension test are shown in Figure 5. When compared with the control group, CEE at doses of $200(P<0.05)$ and $400 \mathrm{mg} / \mathrm{kg}(P<0.01)$, as well as $20 \mathrm{mg} / \mathrm{kg}$ fluoxetine significantly $(P<0.01)$, shortened the duration of immobility in the TST by $48.32,65.66$, and $68.19 \%$, respectively. The antidepressant effect of CEE at the highest dose $(400 \mathrm{mg} / \mathrm{kg})$ was similar to that of fluoxetine $(20 \mathrm{mg} / \mathrm{kg})$. However, the difference from the control group at the lowest dose $(100 \mathrm{mg} / \mathrm{kg})$ was not statistically significant.

3.6. Effects of CEE on Spontaneous Locomotor Activity. In this test, treatments with CEE at doses of 100,200, and $400 \mathrm{mg} / \mathrm{kg}$

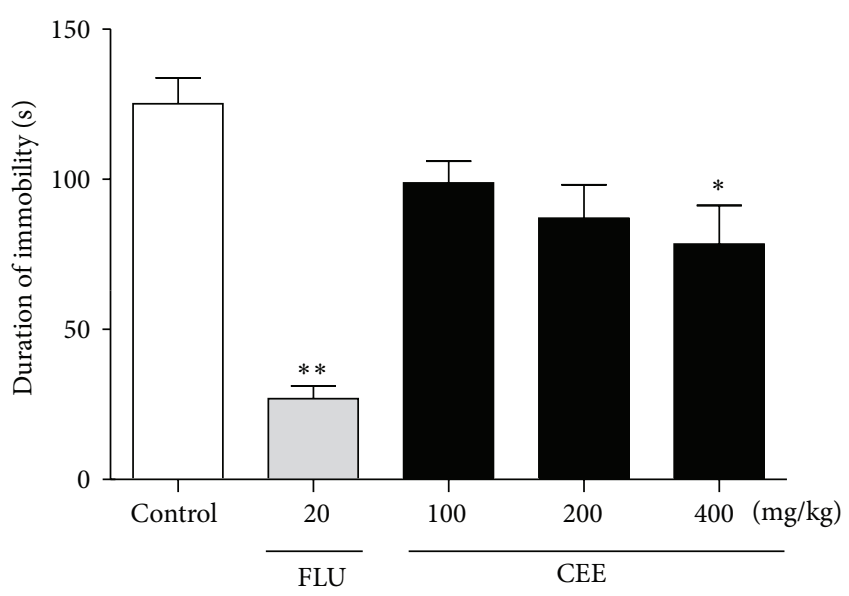

FIGURE 3: Effects of oral administration of CEE (100, 200, or $400 \mathrm{mg} / \mathrm{kg})$ or fluoxetine $(20 \mathrm{mg} / \mathrm{kg})$ on the duration of immobility in the forced swimming test in mice. The total duration of immobility was recorded $1 \mathrm{~h}$ after the last administration. Values are presented as mean \pm S.E.M. $(n=6$ per group $) .{ }^{*} P<0.05,{ }^{* *} P<0.01$ as compared with vehicle control.

exhibited no significant difference in the number of crossings and rearing as compared with the control group (Figure 4).

\subsection{Effects of ASE on the Levels of Monoamine Neurotrans-} mitter in Mice Brain. Results from the ELISA determination of 5-HT in mice brain were shown in Figure 6(a). The pretreatment of $400 \mathrm{mg} / \mathrm{kg} \mathrm{CE}(P<0.05)$ or $20 \mathrm{mg} / \mathrm{kg}$ fluoxetine $(P<0.01)$ significantly elevated the level of 5HT as compared with the control group. Figure 6(b) shows that the oral administration of CEE at 100 or $400 \mathrm{mg} / \mathrm{kg}$ significantly increased DA level in mice brain $[P<0.05$, $P<0.01$, resp.]. Moreover, in this test, the effects of CEE at dose of 100,200 , and $400 \mathrm{mg} / \mathrm{kg}$ presented a trend to increase after 7 consecutive days of treatment. 


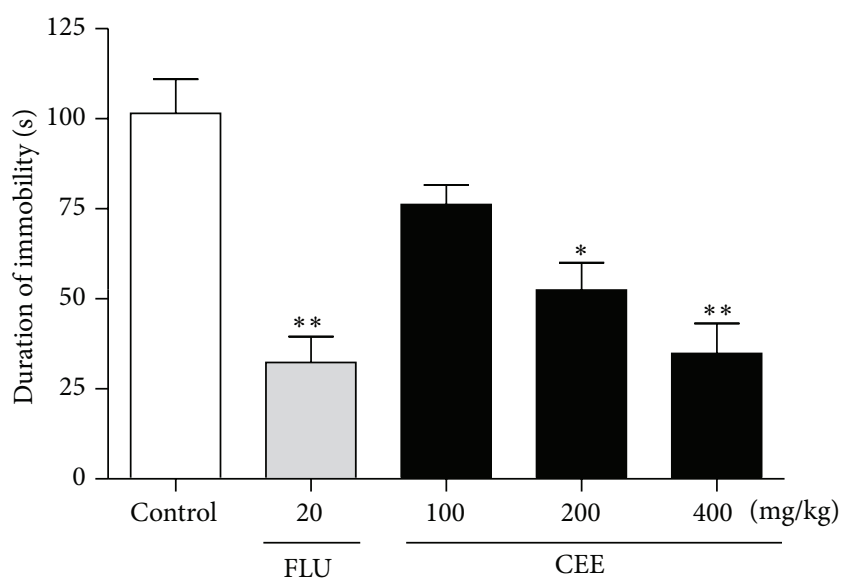

FIGURE 4: Effects of oral administration of CEE (100, 200, or $400 \mathrm{mg} / \mathrm{kg}$ ) or fluoxetine $(20 \mathrm{mg} / \mathrm{kg})$ on the duration of immobility in the tail suspension test in mice. The total duration of immobility was recorded $1 \mathrm{~h}$ after the last administration. Values are presented as mean \pm S.E.M. $\left(n=6\right.$ per group). ${ }^{*} P<0.05,{ }^{* *} P<0.01$ as compared with vehicle control.

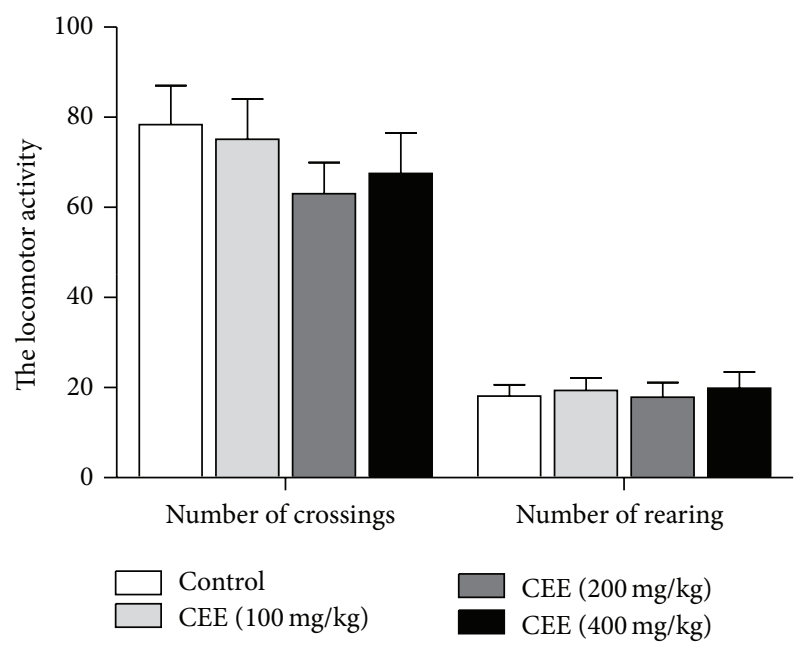

FIGURE 5: Effects of oral administration of CEE (100, 200, or $400 \mathrm{mg} / \mathrm{kg}$ ) on the spontaneous locomotor activity in the open-field test in mice. Values are presented as mean \pm S.E.M. $(n=6$ per group).

\section{Discussion}

The results of these experiments show for the first time that the aqueous extract of the leaves from Camellia euphlebia possesses anxiolytic effects as demonstrated in the lightdark box and elevated plus-maze test, as well as producing antidepressant activities during the forced swimming and tail suspension test.

The animal models mentioned above are considered as the most widely validated tests for assaying anxiolytic and antidepressant substances such as benzodiazepines or amine uptake inhibitors [28-30]. The light-dark box and elevated plus-maze test are the two most commonly used animal models of anxiety with which to screen anxiolytic

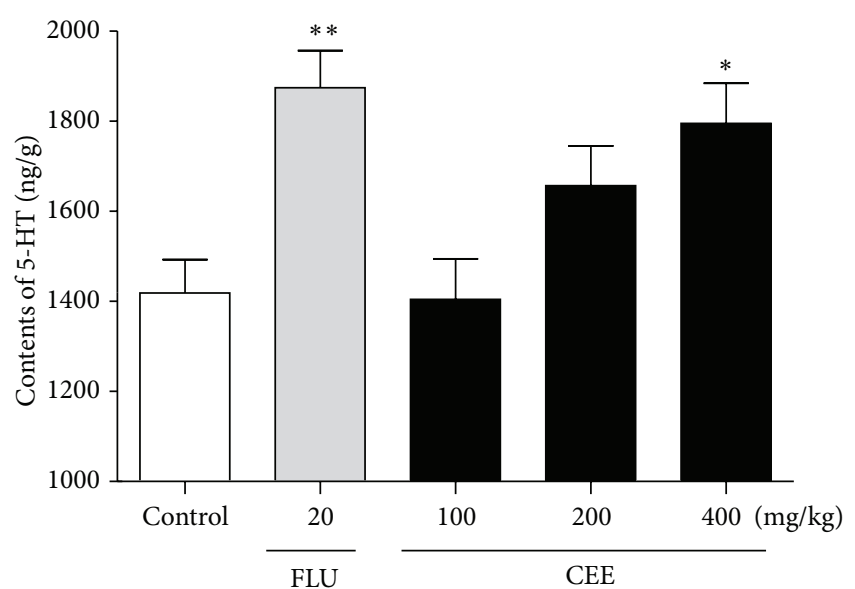

(a)

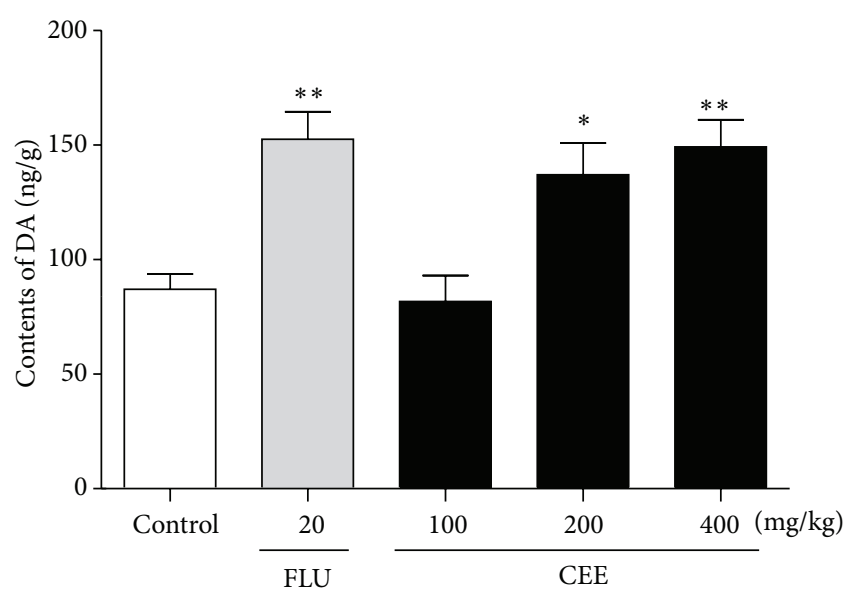

(b)

Figure 6: Effects of CEE $(100,200$, or $400 \mathrm{mg} / \mathrm{kg})$ or fluoxetine $(20 \mathrm{mg} / \mathrm{kg})$ on the contents of 5-HT and DA in the whole brain of mice following the tail suspension test. Values are presented as mean \pm S.E.M. ( $n=6$ per group). ${ }^{*} P<0.05,{ }^{* *} P<0.01$ as compared with vehicle control.

drugs. A natural conflict between the tendency to explore and the initial tendency to avoid an unknown risk occurs when a mouse is exposed to an unfamiliar environment. The exploratory activity reflects the combined effects of these tendencies in novel situations. Thus, in the light-dark box test, drug-induced increases in time spent in the light box and is suggested as an index of anxiolytic activity [31]. Likewise, in the elevated plus-maze model, based on the principle that is exposure to an elevated and open arm maze leads to a conflict, while the number of open arm entries and time spent in the open arm provide a measure of anxietyinduced inhibition of the normal exploratory activity [32]. The forced swimming test and tail suspension test are two behavioral despair models which give an indication of the clinical efficacy of various types of antidepressant drugs in rodents. These animal models are based on the despair or helplessness behavior in response to some inescapable and confined space and are sensitive to various antidepressant drugs. The forced swimming and tail suspension-induced 
state of immobility in animals are claimed to represent a condition similar to human depression and are amenable to be reversed by antidepressant drugs [33].

The results obtained from the forced swimming test and the tail suspension test demonstrate that oral administration of CEE at a high dose of $400 \mathrm{mg} / \mathrm{kg}$ for 7 consecutive days produces a significant reduction in the duration of immobility, since the significant reduction of immobility time elicited by CEE cannot be attributable to any psychostimulant effect in the OFT. In addition, treatment with CEE at a low dose of $100 \mathrm{mg} / \mathrm{kg}$ significantly increased the time spent in the light box in the light-dark box test and the percentage of open arm entries and time spent in open arms in the elevated plusmaze test. This suggests that anxiety and depression show important overlaps, and even anxiety may be an early manifestation of depression as suggested by analyzing the obtained experimental results that mice treated with CEE at a low dose exhibited anxiolytic activities while they demonstrated characteristics of depression with a high dose, although anxiety and depression are considered as two different mental diseases. Moreover, $400 \mathrm{mg} / \mathrm{kg}$ CEE significantly elevated the level of 5-HT and DA. Such an observation suggests that the antidepressant effects of CEE may be caused by the preservation of monoamine neurotransmitters.

The active compounds present in the leaves of Camellia euphlebia are unknown and we cannot discard the possibility that more than one compound is responsible for its behavioral effects. Phytochemical studies have reported the presence of several compounds in the leaf extract of Camellia euphlebia including theanine ( $\gamma$-glutamylethylamide), $\gamma$-aminobutyric acid (GABA), and caffeine [13]. The monoamine hypothesis of depression postulates a pathogenic role for disturbances in the monoaminergic system, involving not only norepinephrine, 5-hydroxytryptamine, and dopamine but also excitatory and inhibitory amino acid receptor families and second messengers [34]. Theanine ( $\gamma$-glutamylethylamide or 5-N-ethylglutamine), a unique amino acid exclusively found in tea, has been reported to increase the level of the inhibitory neurotransmitters, primarily glycine, thus promoting dopamine release, which exert neuroprotective effects [35].

It was reported that the anxiolytic and antidepressant effects of caffeine are ascribed to its antagonistic properties at $\mathrm{A} 1$ and $\mathrm{A} 2 \mathrm{~A}$ adenosine receptors, which interact with other neurotransmitters and proteins [36]. In particular, antagonism of $\mathrm{A} 2 \mathrm{~A}$ receptors increases neurotransmission through dopamine D2 receptors, and antagonism of A1 receptors interacts with $\mathrm{D} 1$ receptors and regulates the release of neurotransmitters such as dopamine, glutamate, and acetylcholine [37, 38].

In addition, GABA is known as an inhibitory neurotransmitter present almost exclusively in the central nervous system, and GABAergic dysfunction causes mood disorders or neurological disorders such as seizures, anxiety, and depression [39]. Recent evidence has suggested the involvement of the GABAergic system in depression and in the mechanism of action of somatic antidepressant treatments [40]. In particular, $\mathrm{GABA}_{\mathrm{B}}$ receptors have been found to be increased in the animal frontal cortex following chronic antidepressant therapies [41, 42]. Most strikingly, in patients with major depression, a reduced level of GABA was found in plasma and cerebrospinal fluid and in occipital cortical brain $[43,44]$. Thus, a deficit in the GABAergic system seems to contribute to both anxiety and depression. Taken together, induced attenuation of GABAergic system by the GABA present in leaves of Camellia euphlebia seems to be part of the therapeutic effects in both anxiety and depression in mice.

It is speculated that the intracellular mechanism of depression involves the CAMP-CREB signal transduction pathway and $\mathrm{Ca}^{2+} /$ calmodulin-dependent pathways. Antidepressant treatment has been reported to upregulate the cAMP-CREB cascade, including increased adenylyl cyclase, upregulation of cAMP-dependent protein kinase, and increased function and expression of CREB, which activates the mRNA expression of BDNF gene in the nucleus, thus contributing to synaptic remodeling and increased neurogenesis [45]. Additionally, CREB can be regulated by $\mathrm{Ca}^{2+}$-dependent protein kinases, which may be excessively activated by intracellular $\mathrm{Ca}^{2+}$ overloading [46]. On the basis of advances in molecular and cellular neurobiology to depression, further studies are needed to clarify the mechanism of action and to determine if administration of $\mathrm{CEE}$ is beneficial for patients with anxiety and depression.

\section{Conclusions}

Our data showed that CEE exerted anxiolytic and antidepressant effects in several classical animal model tests. Additionally, the results indicated that CEE is nontoxic when given acutely and may have a sedative effect at high doses. Overall, this study provides valuable preliminary data on the anxiolytic and antidepressant activities of Camellia euphlebia that should be useful for the planning of future preclinical and clinical studies of this plant medicine.

\section{Conflict of Interests}

The authors have declared that there is no conflict of interests.

\section{Acknowledgments}

This work was supported by the Agriculture Science Technology Achievement Transformation Fund (2013GB2B020531) and National Outstanding Youth Foundation of China (30125034). This work was partly supported by the Fundamental Research Funds for the Central Universities (DUT13JB04).

\section{References}

[1] World Health Organization, The World Health Report: 2001: Mental Health: New Understanding, New Hope, World Health Organization, Geneva, Switzerland, 2001.

[2] E. H. Reynolds, "Brain and mind: a challenge for WHO," The Lancet, vol. 361, no. 9373, pp. 1924-1925, 2003.

[3] H. A. Whiteford, L. Degenhardt, J. Rehm et al., "Global burden of disease attributable to mental and substance use disorders: 
findings from the Global Burden of Disease Study 2010," The Lancet, vol. 382, no. 9904, pp. 1575-1586, 2013.

[4] P. Pacher and V. Kecskemeti, "Cardiovascular side effects of new antidepressants and antipsychotics: new drugs, old concerns?" Current Pharmaceutical Design, vol. 10, no. 20, pp. 2463-2475, 2004.

[5] A. J. Rothschild, "Sexual side effects of antidepressants," Journal of Clinical Psychiatry, vol. 61, no. 11, pp. 28-36, 2000.

[6] P. S. Masand and S. Gupta, "Long-term side effects of newergeneration antidepressants: SSRIS, venlafaxine, nefazodone, bupropion, and mirtazapine," Annals of Clinical Psychiatry, vol. 14, no. 3, pp. 175-182, 2002.

[7] L. Jin, F. Wu, X. Li et al., "Anti-depressant effects of aqueous extract from acanthopanax senticosus in mice," Phytotherapy Research, vol. 27, no. 12, pp. 1829-1833, 2013.

[8] V. S. Pawar, A. Anup, S. Baokar, and H. Shivakumar, "Antidepressant-like effects of Acorus calamus in forced swimming and tail suspension test in mice," Asian Pacific Journal of Tropical Biomedicine, vol. 1, supplement, no. 1, pp. S17-S19, 2011.

[9] J.-H. Kim, S. Y. Kim, S.-Y. Lee, and C.-G. Jang, "Antidepressantlike effects of Albizzia julibrissin in mice: involvement of the 5- $\mathrm{HT}_{1 \mathrm{~A}}$ receptor system," Pharmacology Biochemistry and Behavior, vol. 87, no. 1, pp. 41-47, 2007.

[10] S. S. Kalkunte, A. P. Singh, F. C. Chaves et al., "Antidepressant and antistress activity of GC-MS characterized lipophilic extracts of Ginkgo biloba leaves," Phytotherapy Research, vol. 21, no. 11, pp. 1061-1065, 2007.

[11] Q. Mao, Z. Huang, S. Ip, and C. Che, "Antidepressant-like effect of ethanol extract from Paeonia lactiflora in mice," Phytotherapy Research, vol. 22, no. 11, pp. 1496-1499, 2008.

[12] V. Butterweck, G. Jürgenliemk, A. Nahrstedt, and H. Winterhoff, "Flavonoids from Hypericum perforatum show antidepressant activity in the forced swimming test," Planta Medica, vol. 66, no. 1, pp. 3-6, 2000.

[13] J.-N. Lin, H.-Y. Lin, N.-S. Yang et al., "Chemical constituents and anticancer activity of yellow camellias against MDA-MB231 human breast cancer cells," Journal of Agricultural and Food Chemistry, vol. 61, no. 40, pp. 9638-9644, 2013.

[14] C.-P. Wan, Y.-Y. Yu, S.-R. Zhou, and S.-W. Cao, "Antioxidant and free radical scavenging activity of Camellia nitidissima Chi," Asian Journal of Chemistry, vol. 23, no. 7, pp. 2893-2897, 2011.

[15] Y.-L. Huang, Y.-Y. Chen, Y.-X. Wen, D.-P. Li, R.-G. Liang, and X. Wei, "Effects of the extracts from Camellia nitidssimas leaves on blood lipids," Lishizhen Medicine and Materia Medica Research, vol. 20, no. 4, pp. 776-777, 2009 (Chinese).

[16] X. Xia, J.-J. Huang, Z.-P. Wang, Q. Wang, and W.-G. Pan, "Hypolipidemic effect and acute toxicity of leaves from Camellia nitidissima Chi," Lishizhen Medicine and Materia Medica Research, vol. 24, pp. F0003-F0004, 2013 (Chinese).

[17] Y. R. Cho, J. Y. Chang, and H. C. Chang, "Production of $\gamma$ aminobutyric acid (GABA) by Lactobacillus buchneri isolated from Kimchi and its neuroprotective effect on neuronal cells," Journal of Microbiology and Biotechnology, vol. 17, no. 1, pp. 104109, 2007.

[18] N. Egashira, K. Hayakawa, K. Mishima, H. Kimura, K. Iwasaki, and M. Fujiwara, "Neuroprotective effect of $\gamma$-glutamylethylamide (theanine) on cerebral infarction in mice," Neuroscience Letters, vol. 363, no. 1, pp. 58-61, 2004.

[19] K. Ritchie, I. Carrière, A. De Mendonça et al., "The neuroprotective effects of caffeine. A prospective population study (the Three City Study)," Neurology, vol. 69, no. 6, pp. 536-545, 2007.
[20] L. C. Miller and M. L. Tainter, "Estimation of the ED50 and its error by means of logarithmic-probit graph paper," Experimental Biology and Medicine, vol. 57, no. 2, pp. 261-264, 1944.

[21] B. Costall, A. M. Domeney, P. A. Gerrard, M. E. Kelley, and R. J. Naylor, "Zacopride: anxiolytic profile in rodent and primate models of anxiety," Journal of Pharmacy and Pharmacology, vol. 40, no. 4, pp. 302-305, 1988.

[22] J. N. Crawley, "Exploratory behavior models of anxiety in mice," Neuroscience \& Biobehavioral Reviews, vol. 9, no. 1, pp. 37-44, 1985.

[23] M. C. Carrasco, P. Vicens, J. Vidal, and R. Redolat, "Effects of co-administration of bupropion and nicotinic agonists on the elevated plus-maze test in mice," Progress in NeuroPsychopharmacology and Biological Psychiatry, vol. 30, no. 3, pp. 455-462, 2006.

[24] S. Hogg, "A review of the validity and variability of the elevated plus-maze as an animal model of anxiety," Pharmacology Biochemistry and Behavior, vol. 54, no. 1, pp. 21-30, 1996.

[25] R. D. Porsolt, A. Bertin, and M. Jalfre, "Behavioral despair in mice: a primary screening test for antidepressants," Archives Internationales de Pharmacodynamie Et de Thérapie, vol. 229, no. 2, pp. 327-336, 1977.

[26] L. Steru, R. Chermat, B. Thierry, and P. Simon, "The tail suspension test: a new method for screening antidepressants in mice," Psychopharmacology, vol. 85, no. 3, pp. 367-370, 1985.

[27] A. R. Campos, A. I. S. Barros, F. A. A. Albuquerque, L. K. A. M. Leal, and V. S. N. Rao, "Acute effects of guarana (Paullinia cupana Mart.) on mouse behaviour in forced swimming and open field tests," Phytotherapy Research, vol. 19, no. 5, pp. 441443, 2005.

[28] S. Mora, G. Díaz-Véliz, R. Millán et al., "Anxiolytic and antidepressant-like effects of the hydroalcoholic extract from Aloysia polystachya in rats," Pharmacology Biochemistry and Behavior, vol. 82, no. 2, pp. 373-378, 2005.

[29] G. F. Aragão, L. M. V. Carneiro, A. P. F. Junior et al., "A possible mechanism for anxiolytic and antidepressant effects of alphaand beta-amyrin from Protium heptaphyllum (Aubl.) March," Pharmacology Biochemistry and Behavior, vol. 85, no. 4, pp. 827834, 2006.

[30] J. S. Reis, G. B. Oliveira, M. C. Monteiro et al., "Antidepressantand anxiolytic-like activities of an oil extract of propolis in rats," Phytomedicine, vol. 21, no. 11, pp. 1466-1472, 2014.

[31] M. Bourin and M. Hascoët, "The mouse light/dark box test," European Journal of Pharmacology, vol. 463, no. 1-3, pp. 55-65, 2003.

[32] A. A. Walf and C. A. Frye, "The use of the elevated plus maze as an assay of anxiety-related behavior in rodents," Nature Protocols, vol. 2, no. 2, pp. 322-328, 2007.

[33] V. Castagné, P. Moser, S. Roux, and R. D. Porsolt, “UNIT 8.10A Rodent models of depression: forced swim and tail suspension behavioral despair tests in rats and mice," in Current Protocols in Neuroscience, pp. 11-18, John Wiley \& Sons, 2011.

[34] D. Marazziti, G. Rutigliano, S. Baroni, P. Landi, and L. Dell'Osso, "Metabolic syndrome and major depression," CNS Spectrums, vol. 19, no. 4, pp. 293-304, 2014.

[35] T. Yamada, T. Terashima, S. Kawano et al., "Theanine, $\gamma$ glutamylethylamide, a unique amino acid in tea leaves, modulates neurotransmitter concentrations in the brain striatum interstitium in conscious rats," Amino Acids, vol. 36, no. 1, pp. 21-27, 2009. 
[36] D. R. Lara, "Caffeine, mental health, and psychiatric disorders," Journal of Alzheimer's Disease, vol. 20, no. 1, pp. 239-248, 2010.

[37] B. B. Fredholm, K. Bättig, J. Holmén, A. Nehlig, and E. E. Zvartau, "Actions of caffeine in the brain with special reference to factors that contribute to its widespread use," Pharmacological Reviews, vol. 51, no. 1, pp. 83-133, 1999.

[38] S. Ferré, "An update on the mechanisms of the psychostimulant effects of caffeine," Journal of Neurochemistry, vol. 105, no. 4, pp. 1067-1079, 2008

[39] H. Möhler, "The GABA system in anxiety and depression and its therapeutic potential," Neuropharmacology, vol. 62, no. 1, pp. 42-53, 2012.

[40] B. Luscher, Q. Shen, and N. Sahir, "The GABAergic deficit hypothesis of major depressive disorder," Molecular Psychiatry, vol. 16, no. 4, pp. 383-406, 2011.

[41] A. Pilc and K. G. Lloyd, "Chronic antidepressants and GABA 'B' receptors: a GABA hypothesis of antidepressant drug action," Life Sciences, vol. 35, no. 21, pp. 2149-2154, 1984.

[42] A. Pilc and G. Nowak, "GABAergic hypotheses of anxiety and depression: focus on GABAB receptors," Drugs of Today, vol. 41, no. 11, pp. 755-766, 2005.

[43] G. Sanacora, G. F. Mason, D. L. Rothman et al., "Reduced cortical $\gamma$-aminobutyric acid levels in depressed patients determined by proton magnetic resonance spectroscopy," Archives of General Psychiatry, vol. 56, no. 11, pp. 1043-1047, 1999.

[44] G. Sanacora, G. F. Mason, and J. H. Krystal, "Impairment of GABAergic transmission in depression: new insights from neuroimaging studies," Critical Reviews in Neurobiology, vol. 14, no. 1, pp. 23-45, 2000.

[45] R. S. Duman, "Pathophysiology of depression: the concept of synaptic plasticity," European Psychiatry, vol. 17, no. 3, pp. 306310, 2002.

[46] F. Wu, H. Li, L. Zhao et al., "Protective effects of aqueous extract from Acanthopanax senticosus against corticosterone-induced neurotoxicity in PC12 cells," Journal of Ethnopharmacology, vol. 148, no. 3, pp. 861-868, 2013. 


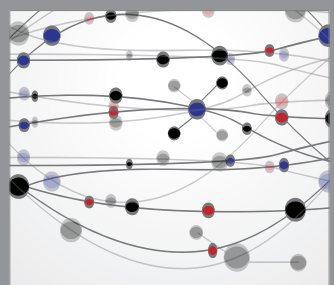

The Scientific World Journal
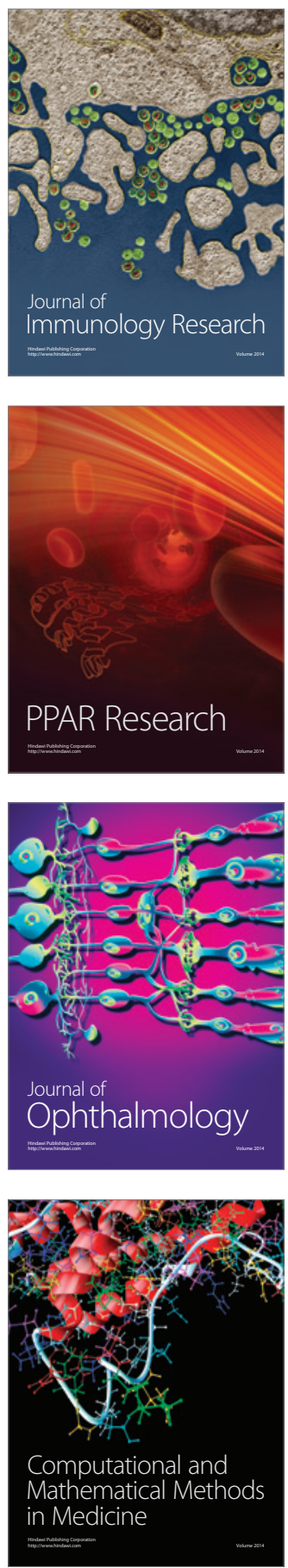

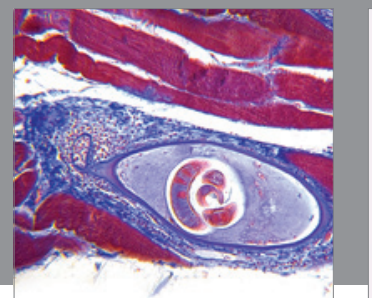

Gastroenterology

Research and Practice
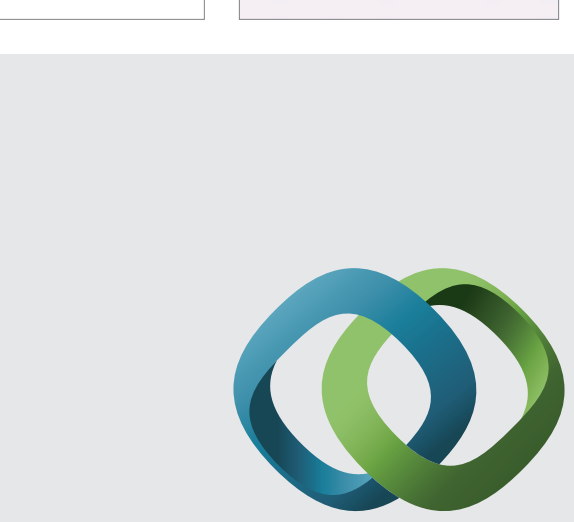

\section{Hindawi}

Submit your manuscripts at

http://www.hindawi.com
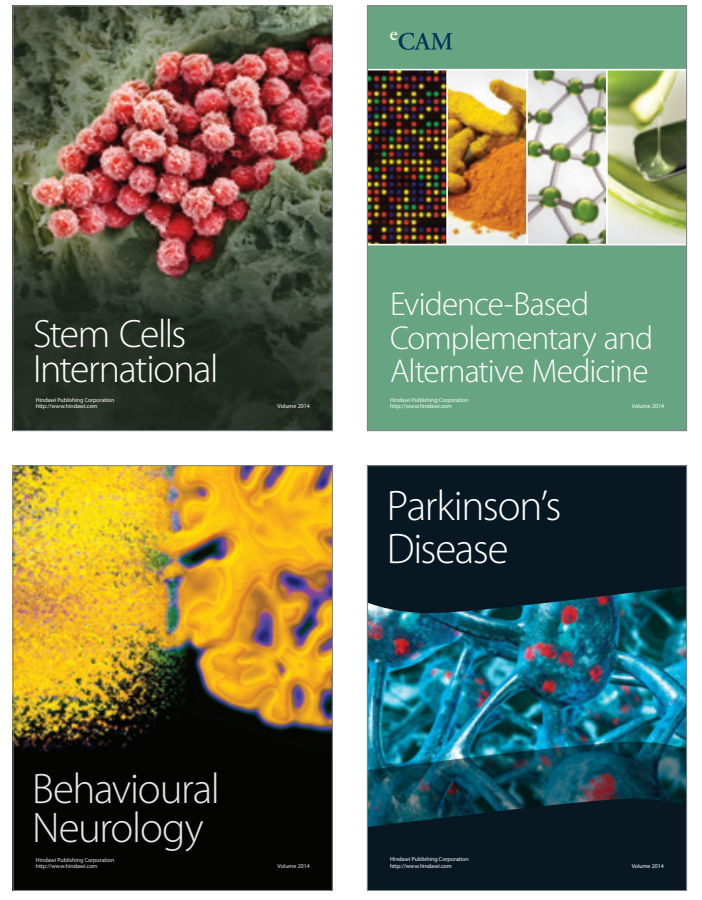
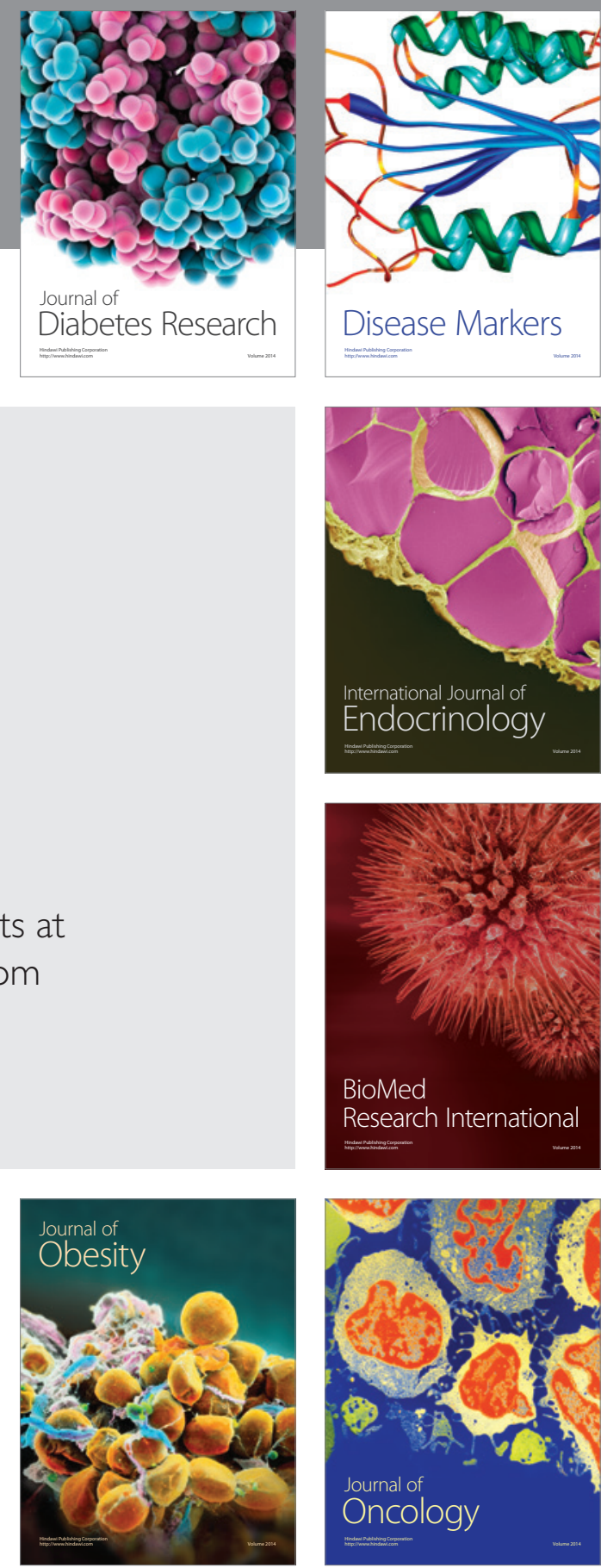

Disease Markers
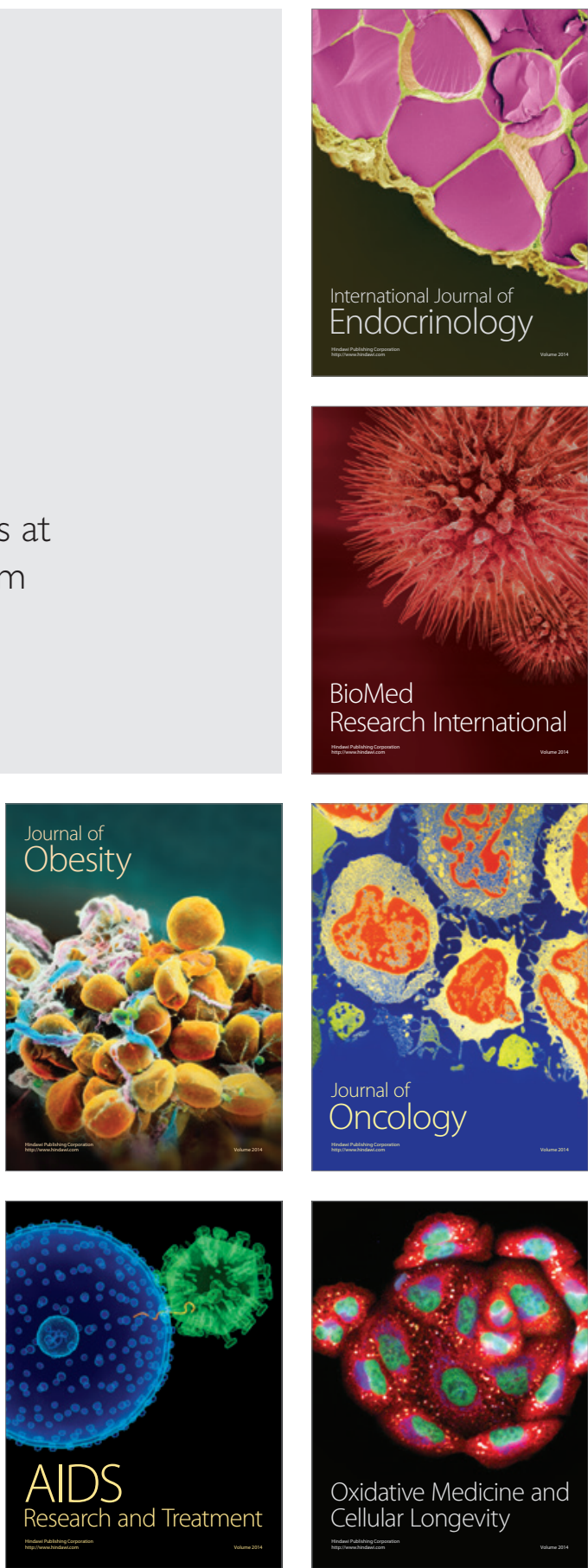